\title{
Characteristics of pregnant women in motor vehicle crashes
}

\author{
H B Weiss, S Strotmeyer
}

See end of article for authors' affiliations

....................

Correspondence to: Dr Harold B Weiss, Associate Director and Assistant Professor, Center for Injury Research and Control, University of Pittsburgh, 200 Lothrop St, Suite B400, Pittsburgh 15213, PA, USA;

hweiss@injurycontrol.com
Injury Prevention 2002;8:207-2 10

Objectives: Motor vehicle crashes are the leading cause of hospitalized trauma during pregnancy. Maternal injury puts the fetus at great risk, yet little is known about the incidence, risks, and characteristics of pregnant women in crashes.

Setting and methods: Police reported crashes were analyzed from the National Automotive Sampling System Crashworthiness Data System. Since 1995, this system recorded pregnancy/trimester status. Pregnant and non-pregnant women 15-39 years of age were compared by age, driver status, seat belt use, and treatment. Belt use and seating position were examined by trimester.

Results: There were 427 pregnant occupants identified (weighted $n=32810,2.6 \%$, SE 12 585, rate $13 / 1000$ person years). The mean age was 24.9 compared with 24.8 years (pregnant $v$ non-pregnant). Cases were distributed by trimester as follows: first $29.8 \%$, second $36.4 \%$, and third $33.8 \%$. Pregnant women were drivers $70 \%$ of the time compared with $71 \%$ for non-pregnant women. No belt use was $14 \%$ compared with $13 \%$ (pregnant $v$ non-pregnant). Mean injury severity was lower for pregnant women but they were more likely to transported or hospitalized. Improper belt use decreased after the first trimester and there was little change in driver proportion by trimester. Third trimester hospitalization rates increased.

Conclusions: Pregnant occupants in crashes have similar profiles of restraint use, driver status, and seat position but different treatment indicators compared to non-pregnant occupants. Trimester status has relatively little impact on crash risk, seating position or restraint use. Undercounting of pregnant cases was possible, even so, $1 \%$ of all births were reported to be involved in utero in crashes. Little research has focused on developmental outcomes to infants and children previously involved in exposure to these crashes.
M otor vehicle crashes are the leading cause of traumatic fetal injury mortality, ${ }^{1}$ and the leading cause of death $^{23}$ and serious trauma ${ }^{4}$ during pregnancy. Maternal injury may put the fetus at great risk, yet little is known from population based studies about the characteristics and risks of pregnant women involved in motor vehicle crashes. Such information is necessary to begin to understand the magnitude of fetal motor vehicle trauma exposure, which women are at highest risk, what role occupant behaviors play, and to put the problem into the proper perspective with other crash, environmental exposure, and reproductive and child health issues.

\section{PARTICIPANTS AND METHODS}

Data were analyzed from the 1995-99 National Automotive Sampling System Crashworthiness Data System (NASS/CDS). NASS/CDS crashes are a probability sample of police reported US traffic way crashes that involve property damage and/or personal injury. ${ }^{5}$ Weighted estimates are representative of the US population. Since 1995, this system has recorded pregnancy and trimester status derived from interviews and medical record reviews. Pregnant and non-pregnant women 15-39 years of age were compared by age, driver status, seat belt use, and treatment level. Driver status, restraint use, and crash risk were examined by trimester. After removing one pregnancy associated case and 13 non-pregnancy associated records with large weights (those with weights >20 000), there were 427 unweighted pregnancy related and 11972 non-pregnancy cases identified from which annualized weighted estimates were derived. Standard errors were computed for point estimates derived from the entire sample using SUDAAN software (Research Triangle Institute, North Carolina).
Incidence rates were calculated per 1000 person years. For the pregnant population, the persons at risk (denominators) were derived from age specific US birth data and adjusted downward to account for the nine month period of gestation and the assumption that most pregnancies would not be detectable in the first month of pregnancy. For example, if there were 100000 live births per year, multiplying 100000 by $8 / 12$ represents the actual person years of exposure-that is, the person years among which women could realistically have had their pregnancies identified. Lowering the denominator has the net effect of adjusting the estimated rates for pregnant women upwards. For the non-pregnant rates, person years and annual population rates are equivalent.

\section{RESULTS}

There were an estimated (weighted) 32810 (SE 12 585) pregnant occupants annually involved in crashes or $2.6 \%$ of all women in crashes from the ages of 15-39. This translates to a crash rate among pregnant women of $13 / 1000$ person years (1.3\%). For comparison, there were 1251269 (SE 127 522) women ages 15-39 not reported pregnant (rate 26/1000 person years) and 23188 (SE 3700) infants (rate 6.1/1000 person years) reported in crashes. The mean age for pregnant women was 24.9 versus 24.8 for non-pregnant women. Among pregnant women, the highest crash rate per 1000 live births was in the youngest age group. In peak childbearing years (ages 20-29), at least 3\% of all women involved in a police reported crash were pregnant.

Abbreviations: NASS/CDS, National Automotive Sampling System Crashworthiness Data System; SE, standard error 
Table 1 Rate calculations between women ages 15-39 in crashes by pregnancy status, National Automotive Sampling System Crashworthiness Data System, 1995-99*

\begin{tabular}{|c|c|c|}
\hline \multirow[b]{2}{*}{ Rate calculations } & \multicolumn{2}{|c|}{ Reported pregnancy status } \\
\hline & Pregnant & $\begin{array}{l}\text { Not } \\
\text { pregnant }\end{array}$ \\
\hline \multicolumn{3}{|c|}{$\begin{array}{l}\text { Annualized age specific rate per } 1000 \text { live births (using } 1997 \text { live } \\
\text { births as denominator) }\end{array}$} \\
\hline $15-19(n=7478, S E=3265)$ & 15 & NA \\
\hline $20-24(\mathrm{n}=8230, \mathrm{SE}=2187)$ & 9 & NA \\
\hline $25-29(n=8850, S E=10048)$ & 8 & NA \\
\hline $30-34(n=6164, S E=1737)$ & 7 & NA \\
\hline $35-39(n=2088, S E=558)$ & 5 & NA \\
\hline All ages $(n=32810, S E=12585)$ & 9 & NA \\
\hline \multicolumn{3}{|c|}{$\begin{array}{l}\text { Annualized age specific rate per } 1000 \text { person years (assuming } \\
\text { pregnancy is detectable over } 8 \text { months) }\end{array}$} \\
\hline $15-19$ & 23 & 44 \\
\hline $20-24$ & 13 & 35 \\
\hline $25-29$ & 12 & 22 \\
\hline $30-34$ & 10 & 18 \\
\hline $35-39$ & 8 & 18 \\
\hline All ages & 13 & 26 \\
\hline
\end{tabular}

Pregnant women were more likely than non-pregnant women to be transported to the emergency department and released or hospitalized. Airbag deployment did not differ much between pregnant and non-pregnant cases; airbags were deployed among 15\% of the pregnant cases and 13\% of the non-pregnant cases. Other selected comparisons between the pregnant and not reported as pregnant cases are detailed in tables 1 and 2 .

Most pregnant cases had the trimester reported (87.8\%; $\mathrm{n}=28$ 281, SE 12 758). Omitting the pregnancy associated cases without trimester mention $(n=4529 ; 13.8 \%$, SE 1798), they were distributed as follows: first trimester $24.6 \%$ $(n=6968$, SE 9721), second 39.1\% $(n=11060$, SE 2722), and third 33.8\% $(\mathrm{n}=10254, \mathrm{SE} 2983)$. Third trimester cases $(n=2431$, SE 998) were more likely to be hospitalized than earlier trimester cases $(67.2 \%$ of the hospitalized cases were third trimester). The proportion of cases that were drivers $(\mathrm{n}=18779 ; 66.4 \%$, SE 11735$)$ were distributed as follows: first trimester $28.6 \% \quad(n=5367$, SE 9773$)$, second $42.9 \%$ $(n=8065$, SE 1850$)$, and third 28.5\% $(n=5346, S E 1362)$. Among pregnant women, $13.7 \%(n=4395$, SE 1686) were reported by the police not to be using any restraint (excludes cases missing restraint use variable).

\section{DISCUSSION}

The crash risk for reported pregnant occupants in these data was about one half that of all women in the same age range. However, one should use caution before presuming from these data that pregnant women are at lower crash risk. Identifying pregnancy status from crash and medical records is not always easy for crash investigators because early pregnancy cases may not be known or reported. Further, many women are not interviewed directly, resulting in reliance on written records that may or may not exist, especially for events that often do not result in hospital visits. Also, the methods for determining pregnancy and the completeness and accuracy of pregnancy status in NASS/CDS has not, to our knowledge, been externally validated (for example, by matching cases forward in time to birth certificates). Furthermore, NASS/CDS coding rules state that when pregnancy status is unknown cases are to be assigned to the "Female not-reported pregnant" category. ${ }^{6}$ There is evidence from a statewide injury inpatient study that the hospitalized crash injury rate of pregnancy associated cases is not lower compared to that of all women of reproductive age (even after length of stay adjustment). ${ }^{4}$

The data also lack patient follow up with the result that little is known or tracked about non-fatal fetal crash outcomes. Motor vehicle crashes are probably a larger threat to fetuses then to infants due to increased crash involvement (as shown in this study), increased vulnerability due to dependence on placental circulation for survival, vulnerability to sensitive developmental periods of risk, and perhaps comparatively less

Table 2 Selected comparisons between women ages 15-39 in crashes by pregnancy status, National Automotive Sampling System Crashworthiness Data System, 1995-99*

\begin{tabular}{|c|c|c|c|c|}
\hline \multirow[b]{3}{*}{ Selected comparisons } & \multicolumn{4}{|c|}{ Reported pregnancy status } \\
\hline & \multicolumn{2}{|l|}{ Pregnant } & \multicolumn{2}{|l|}{ Not pregnant } \\
\hline & No $(\%)$ & SE & No (\%) & SE \\
\hline Number of cases, 1995-9 (unweighted) & 427 & - & 11972 & - \\
\hline Annualized number of cases (weighted) & 32810 & 12585 & 1251269 & 127522 \\
\hline \multicolumn{5}{|c|}{ Number ( $\%$ within age group) that were drivers } \\
\hline $15-19$ & $5370(72)$ & 2731 & $217584(55)$ & 38104 \\
\hline $20-24$ & $5482(67)$ & 1671 & $222105(76)$ & 39222 \\
\hline $25-29$ & $5654(64)$ & 9746 & $164136(81)$ & 10816 \\
\hline $30-34$ & $4438(72)$ & 1284 & $137751(75)$ & 18767 \\
\hline $35-39$ & $1872(90)$ & 542 & $147268(83)$ & 13939 \\
\hline All ages & $22816(70)$ & 11662 & $888843(71)$ & 106928 \\
\hline \multicolumn{5}{|l|}{ Treatment level (\% within group) } \\
\hline No treatment & $7908(24)$ & 2868 & $635197(51)$ & 76723 \\
\hline Transport and release/treated at scene & $19217(59)$ & 10546 & $422593(34)$ & 60488 \\
\hline Hospitalized or fatal & $4431(14)$ & 1345 & $57857(5)$ & 13092 \\
\hline Other or unknown & $1254(4)$ & 750 & $135622(11)$ & 11387 \\
\hline Total & $32810(100)$ & 12585 & $1251270(100)$ & 127522 \\
\hline \multicolumn{5}{|l|}{ Police reported belt use } \\
\hline None used & $4395(14)$ & 1696 & $158021(13)$ & 42023 \\
\hline Lap and shoulder & 19805 (59) & 10546 & 704779 (59) & 79038 \\
\hline Lap or shoulder & $824(3)$ & 391 & $29280(2)$ & 5916 \\
\hline Belt used, type not specified & $5716(18)$ & 3162 & $240731(20)$ & 155053 \\
\hline Other response & $68(0)$ & 59 & $1321(0)$ & 284 \\
\hline No police indication & $1970(6)$ & 628 & $57585(5)$ & 18588 \\
\hline
\end{tabular}


protection from the in utero environment than infants receive from safety seats.

Given the potential numbers of exposed fetuses, longitudinal research on non-fatal fetal outcomes is needed. Fetal trauma exposure has received very little attention among reproductive and environmental scientists and funding agencies. This is mainly due to: (1) major deficiencies in the way fetal trauma related deaths are coded in vital statistics; (2) the lack or poor quality of pregnancy status variables and follow up in most injury surveillance systems; (3) unfamiliarity by many reproductive health researchers with injury science and the large societal burden of injury; and (4) the difficulty of attributing adverse birth outcomes and developmental problems many months or years after trauma. However, the recent convergence of several research lines suggests reasons why this problem should receive urgent attention.

The first important research line comes from reports by the National Highway Traffic Safety Administration, and others, which have shown that between 1975 and 1990, primarily because women are driving more miles, the number of fatal crashes involving female drivers has increased dramatically by $62 \% .^{7}$ This large increase in exposure may have resulted in a poorly documented trauma induced epidemic of fetal loss, fetal injury, and adverse reproductive outcomes. While there is indirect corroborating evidence from national vital statistics data of similar increases in neonatal deaths due to maternal trauma during this time span, ${ }^{8}$ there is currently no way of confirming this because of the documentation problems mentioned above.

The second research line emerges from looking at the relationship between stress reactions and preterm labor. Although much of this work has focused on the stress of poverty, abuse and social disparities, trauma itself is a widespread but often overlooked trigger of high levels of stress. It has recently been estimated that $9 \%$ of survivors of serious crashes develop significant post-traumatic stress symptoms and that many other survivors have post-traumatic stress disorder-like reactions. ${ }^{9}$ In fact, motor vehicle crashes may be the leading cause of post-traumatic stress disorder, providing fertile opportunities for stress/reproductive research. One thread suggests that stress either very early in pregnancy or in the 24-28th weeks of pregnancy leads to a twofold increase in the risk of autism. ${ }^{10}$ Since autism is usually not apparent until a child is 1-3 years of age it may be difficult to trace back to the original events. Recently, a study suggested that experiencing a stressful event "during the periconceptional period" was associated with increased congenital anomalies including heart and neural tube defects and cleft lips and palates. ${ }^{11}$

The third research line comes from cohort studies of hospitalized injured pregnant women that linked to birth records. Wolf et al reported in a 1980-88 retrospective cohort study of seat belt use and pregnancy outcome after a motor vehicle crash that unrestrained pregnant women were more likely to give birth to a low birthweight baby and more likely to give birth within 48 hours after the motor vehicle crash than pregnant women drivers who were not restrained. ${ }^{12}$ Recently, a retrospective cohort study was reported that looked at pregnancy outcomes from hospitalized injury (all types) during pregnancy in Washington State from 1989-97..$^{8}$ It reported increased risks for placental abruption, low birth weight, prematurity, and fetal death.

The fourth line of research focuses on the risk of fetal mortality versus infant mortality from motor vehicle crashes. Drawing conclusions from a 15 state study of fetal death certificates, Weiss et al provided evidence that fetal motor vehicle injury mortality rates were much greater than that of infants. $^{13}$

The fifth research line is not as strong because the evidence of harm does not come from population based studies, but from several case series. An example is the report of Baethmann et al on the effects of maternal trauma on surviv-

\section{Key points}

- At least $1 \%$ of all children are involved in utero in police reported crashes.

- Pregnant occupants in crashes have similar profiles of restraint use, driver status, and seat position as nonpregnant occupants.

- Pregnant occupants in crashes are more likely to be transported for less serious injury.

- Trimester status may have only minor bearing on the risk of being in a crash, seating position or restraint use.

- Little research has focused on the developmental outcomes to children involved in these events.

ing fetuses. ${ }^{14}$ Seven mothers had motor vehicle crashes, two had blunt abdominal trauma. Later clinical symptoms in the nine children included movement disorders and cerebral palsy among other findings. The causative role of maternal accidents was extremely likely in one patient, and probable but "unproved" in the remaining cases. Another more cogent example is from Strigini et al..$^{15}$ In five consecutive cases of fetal intracranial hemorrhage, the similarity of histories involving minor maternal physical trauma (three motor vehicle related and two falls), together with the absence of any known factor predisposing to fetal intracranial hemorrhage, suggested that minor trauma was at least a contributing factor to the observed pathology. Other similar but smaller case series or reports have been reported ${ }^{16}$ raising the issue of trauma as a true teratogen (defined by the US Environmental Protection Agency as "The introduction of nonhereditary birth defects in a developing fetus by exogenous factors such as physical or chemical agents acting in the womb to interfere with normal embryonic development").

Separately, each of these research lines raises interesting but somewhat circumscribed issues. Taken together, with the conservative national estimate on pregnancy related crashes from the current study, raises cause for concern. They reveal that in utero motor vehicle crash exposure occurs in tens of thousands of pregnancies every year, is directly responsible for at least hundreds of fetal deaths annually, that the problem has probably increased substantially over the last two and one half decades, and that we are only just now beginning to understand the types and potential for serious non-fatal reproductive and developmental outcomes later in life that may be linked to the original traumatic insult to the environment of the developing fetus.

\section{CONCLUSION}

Trauma should be viewed in the light of other major environmental threats to the fetus. Three per cent of pregnancies involve binge drinking. ${ }^{17}$ Twelve per cent of pregnancies involve cigarette smoking. ${ }^{18}$ Assuming that pregnant women are injured at the same rate as all women of reproductive age we estimate that about $8 \%$ of all pregnancies are exposed to a hospital treated injury (from national emergency department data of all injuries, not just motor vehicles, and age specific birth rates). Unlike many other important environmental threats, it is not well known how or to what extent trauma exposures contribute to adverse developmental outcomes.

There is need to better track pregnancy related crashes (and other pregnancy related injuries) and their outcomes in state and national surveillance systems. We need to better understand how to protect pregnant women from being in a crash and if in a crash, how to better protect them. Finally, we need to know much more about the long term developmental, physical, and cognitive consequences on the children who are impacted by this problem so very early in life. 


\section{ACKNOWLEDGEMENTS}

We wish to acknowledge the timely and expert assistance of staff from the National Center for Statistics and Analysis in the National Highway Traffic Safety Administration for computing the standard errors used in this report.

\section{Authors' affiliations}

H B Weiss, S Strotmeyer, University of Pittsburgh, Center for Injury Research and Control (CIRCL)

\section{REFERENCES}

1 Weiss $\mathbf{H}$. The epidemiology of traumatic injury-related fetal mortality in Pennsylvania, 1995-1997: the role of motor vehicle crashes. Accid Anal Prev 2001;33:449-54

2 Rochat R, Koonin L, Atrash $\mathrm{H}$, et al. Maternal mortality in the United States: report from the maternal mortality collaborative. Obstet Gynecol 1988;72:91-7

3 Weiss H. Causes of traumatic death during pregnancy (letter). JAMA 2001;285:2854-5

4 Weiss H. Pregnancy-associated injury hospitalizations in Pennsylvania, 1995. Ann Emerg Med 1999:34:626-36.

5 US Department of Transportation, National Highway Traffic Safety Administration. National Automotive Sampling System (NASS) crashworthiness data system, analytical user's manual, 1999 file. Washington, DC: US Department of Transportation, NHTSA, 2000

6 US Department of Transportation, National Highway Traffic Safety Administration. National Center for Statistics and Analysis, National Automotive Sampling System, 1997. Crashworthiness Data System, Data collection coding and editing manual. Washington, DC: US Department of Transportation, NHTSA, 1997.
7 Haapaniemi P. Women's highway deaths on the rise. Traffic Safety 1996:96:6-11

8 Schiff $M$, Holt V, Daling J. Pregnancy-associated injury hospitalizations: maternal and fetal outcomes. Paediatr Perinat Epidemiol 2001;15(4):A29.

9 Kessler RC, Sonnega A, Bromet E, et al. Posttraumatic stress disorder in the National Comorbidity Survey. Arch Gen Psychiatry 1995; 52:1048-60.

10 Beversdorf D. Stress during pregnancy linked to autism. San Diego, CA: Society for Neuroscience, 2001.

11 Carmichael SL, Shaw GM. Maternal life event stress and congenital anomalies. Epidemiology 2000;1 1:30-5

12 Wolf ME, Alexander BH, Rivara FP, et al. A retrospective cohort study of seatbelt use and pregnancy outcome after a motor vehicle crash. $J$ Trauma 1993;34: 116-9

13 Weiss HB, Songer TJ, Fabio A. Fetal deaths related to maternal injury JAMA 2001;286:1863-8.

14 Baethmann M, Kahn T, Lenard HG, et al. Fetal CNS damage after exposure to maternal trauma during pregnancy. Acta Paediatr 1996;85:1331-8.

15 Strigini FA, Cioni G, Canapicchi R, et al. Fetal intracranial hemorrhage: is minor maternal trauma a possible pathogenetic factor? Ultrasound Obstet Gynecol 2001 ; 18:335-42.

16 Mancini J, Lethel V, Hugonenq C, et al. Brain injuries in early foetal life: consequences for brain development. Dev Med Child Neurol 2001:43:52-5.

17 Substance Abuse and Mental Health Services Administration. Summary of findings from the 1999 National Household Survey on Drug Abuse [web page], 2000. Accessed 20 July 2001 (http:// www.samhsa.gov/oas/FemAlcTob.pdf)

18 Ebrahim SH, Floyd RL, Merritt RK 2nd, et al. Trends in pregnancy-related smoking rates in the United States, 1987-1996. JAMA 2000;283:361-6.

\section{Injury Prevention contributor wins Ig Nobel Award}

One of our reviewers and occasional contributor, Peter Barss, a professor in the Department of Epidemiology at McGill, was the recipient of this year's Ig Nobel Prize for his pioneering research on "Injuries due to falling coconuts". Although this award is a spoof, being hit with a coconut weighing between 2 and 4 $\mathrm{kg}$ may not be a laughing matter. Far more amusing are some of the past Ig Nobel winners in other fields: Physics 2001 "Why shower curtains billow inward"; Psychology 2001 "An ecological study of glee in small groups of preschool children"; Peace 2000, awarded to the British Royal Navy for ordering its sailors to stop using live cannon shells and simply shout "Bang!" instead. Other recipients include: Medicine 1993, "Acute management of zipper-entrapped penis"; Mathematics 1993, for calculating the exact odd that Mikhail Gorbachev is the Antichrist; Literature 1999, for the six page description of the proper way to make a cup of tea, and Public Health 1996, for "Transmission of gonorrhoea through an inflatable doll". (The award is a creation of the journal, Annals of Improbable Research; contributed by Barry Pless.)

\section{Glamorizing hazards}

Occasionally, an advertisement will disturb the safety conscious consumer. Perhaps it grabs attention by glamorizing a risky activity or depicting a dangerous location. It might show people biking, snowboarding, or driving without the proper protection. Advertising has tremendous power, not only to sell products but to sell attitudes. It is important for advertisers to send a responsible safety message to the public. The Canada Safety Council has challenged a number of lifestyle advertisements, including some that featured people walking on railway tracks, reckless driving, and lack of a helmet or vehicle restraint. What can you do if you see a commercial or print ad that seems to promote unsafe behavior? First, contact the advertiser with the details of your concern. Names and addresses of companies and their CEOs are available on web sites and in business directories. If you're not satisfied with the advertiser's response, complain to Advertising Standards Canada, the self regulating body for the industry. ASC administers the Canadian Code of Advertising Standards, which has a clause on safety:

"Advertisements must not without reason, justifiable on educational or social grounds, display a disregard for safety or depict situations that might encourage unsafe or dangerous practices or acts."

In its 2000 Ad Complaints Report, ASC describes three sanctioned television commercials: a laundry detergent ad where a teenager was buried by dirt from a dump truck, then emerged unharmed; a bakery ad with workers inside a grain silo looking up as grain poured into the silo from the top; and a financial ad that showed a lantern intended only for outdoor use being used in an enclosed space. If you have safety concerns about an ad campaign, provide the Canada Safety Council with a full description. We may support your request that the advertising be changed or withdrawn. (Reproduced from President's Perspective, Safety Canada, the member newsletter of Canada Safety Council, Vol XLV, No 4, October 2001. The newsletter can be read at www.safety-council.org.) 